\title{
AVALIAÇÃO DO USO DE UMA PROPOSTA DE LOUSA DIGITAL DE BAIXO CUSTO
}

\author{
Yure Vieira Sampaio Albuquerque, IFCE, vurevsal@gmail.com Antônio \\ José Melo Leite Junior, IUVI/UFC, melojr@virtual.ufc.br Gabriel \\ Antoine Louis Paillard, IUVI/UFC, gabriel@ virtual.ufc.br Henrique \\ Sérgio Lima Pequeno, IUVI/UFC, henrique@ virtual.ufc.br Natal \\ Anacleto Chicca Junior, IUVI/UFC, natal@ virtual.ufc.br Clemilson \\ Costa dos Santos, IUVI/UFC, clemilson.santos@virtual.ufc.br Auzuir \\ Ripardo de Alexandria, IFCE, auzuir@gmail.com \\ George Allan Menezes Gomes, IUVI/UFC, george@virtual.ufc.br
}

\section{RESUMO}

As lousas digitais têm se tornado um importante recurso didático onde o usuário é capaz de escrever, manipular objetos interativos e realizar apresentações com simulações ou vídeos. No entanto, os custos envolvidos com aquisição, configuração, uso e manutenção geralmente restringem o acesso a tal tipo de solução educacional. O presente trabalho propõe um modelo de lousa digital de baixo custo, baseado no emprego de captura de luz infravermelha. Para a análise de possíveis falhas e da eficiência da solução proposta em relação à manipulação de conteúdos digitais, foram realizados testes envolvendo a participação de vinte voluntários com perfis específicos, sendo dezessete estudantes e três docentes. Após avaliações de caráter quantitativo e qualitativo, os bons resultados obtidos apontaram que o sistema apresenta uma baixa taxa de falhas e uso adequado, indicando ainda possíveis desdobramentos futuros e, com seu posterior amadurecimento, viabilizando uma maior democratização do processo de ensino-aprendizagem.

Palavras Chaves: Lousa digital, luz infravermelha, avaliação de uso.

\section{EVALUATING THE USE OF A LOW-COST DIGITAL WHITEBOARD PROPOSAL}

\section{ABSTRACT}

Digital whiteboards have become an essential educational resource where the user can write, manipulate interactive objects, and make presentations with simulations or videos. However, the costs involved with acquiring, configuring, using and maintaining restrict access to such an educational solution. The present work proposes a low-cost digital whiteboard model based on the infrared light capture. To analyze possible failures and the efficiency of the proposed solution about the manipulation of digital content, we made tests involving the participation of twenty volunteers with specific profiles, seventeen students, and three teachers. After quantitative and qualitative evaluations, the good results showed that the system has a low failure rate and fair use, indicating possible future developments and, with its later maturation, enabling greater democratization of the teaching-learning process.

Keywords: Digital whiteboard, infrared light, use evaluation.

\section{Introdução}

O quadro branco tradicional é uma forma muito difundida de auxílio a uma apresentação oral, sendo geralmente usado quando é necessário ilustrar diagramas, gráficos, slides ou mesmo fazer anotações, estando presente na maioria das universidades e escolas. $\mathrm{O}$ quadro branco possui duas características que o tornam uma ferramenta bastante utilizada: facilidade de uso e rapidez. Não é necessário ter conhecimento além do uso do pincel de tinta para desenhar e escrever. Além disso, a utilização de um quadro branco tradicional é rápida porque não requer conhecimento prévio, sendo a velocidade de sua resposta limitada unicamente pela desenvoltura na qual o usuário é capaz de desenhar ou escrever. 
Entretanto, existem algumas limitações apresentadas por esse tipo de ferramenta, como, por exemplo, o tempo que os discentes gastam para copiar o conteúdo escrito ou desenhado, reduzindo o dinamismo e a fluidez da apresentação, uma vez que o docente deve interromper a apresentação para tal (DANTAS, 2015).

Com o propósito de sanar essas limitações, diversos sistemas de lousas digitais interativas foram lançados, empregando variadas técnicas para detecção de interações do usuário. Apesar de proporcionar uma boa experiência ao usuário, esse tipo de tecnologia tem sua disseminação moderada, devido principalmente ao alto custo de aquisição (atualmente variando na casa de US\$ $1.500,00$ a US\$ 2.000,00 apenas o sistema da lousa digital, desconsiderando projetor multimídia e microcomputador, geralmente necessários) e pela necessidade de execução de procedimentos especiais para instalação e calibragem (DANTAS, 2015).

Tais custos acabam tornando bastante proibitivo o emprego desse tipo de solução, particularmente para instituições de ensino pequenas ou públicas, que normalmente não dispõem de muitos recursos. No entanto, para contornar o obstáculo do custo, pode-se adotar outras formas de detecção, tendo como princípio de funcionamento a luz infravermelha, onde, através de um software que interpreta imagens captadas por uma câmera de vídeo, é possível realizar interações utilizando uma caneta emissora de luz (LEE, 2008).

O objetivo deste trabalho é expor o processo de desenvolvimento de uma lousa digital de baixo-custo, utilizando luz infravermelha como forma de interação entre o usuário e o sistema. Para tanto, serão apresentadas e discutidas as etapas necessárias de definição, construção e teste, incluindo avaliações quantitativa e qualitativa, destacando os respectivos resultados obtidos (Figura 1).

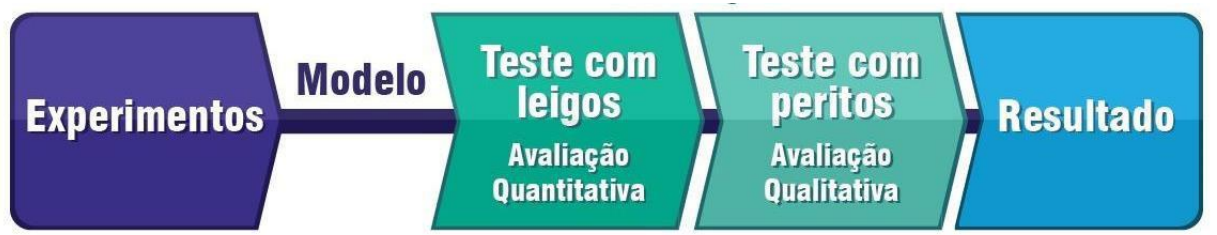

Figura 1 - Processo de desenvolvimento e avaliação da lousa digital proposta.

Fonte: os autores, 2019.

Este trabalho encontra-se dividido em cinco seções específicas. Na seção 2 são analisados alguns trabalhos relacionados; na seção 3 são apresentados os materiais e métodos empregados na construção da solução proposta; na seção 4 são expostos e avaliados os testes realizados; por fim, a seção 5 apresenta algumas conclusões do uso da lousa interativa construída e possíveis desdobramentos para trabalhos futuros.

\section{Trabalhos Relacionados}

De uma forma geral, atualmente existem diversos modelos de lousas digitais no mercado. No trabalho de Soares (2009), em particular, são descritas as principais tecnologias que podem ser utilizadas para sua implementação:

- Resistiva: o sistema é composto por duas placas separadas por uma camada de ar. Quando é executado um toque ou pressão na camada superior, por dedo, caneta ou qualquer outro objeto, ocorre um contato, fechando um circuito elétrico entre essas duas superfícies. Desta forma, é possível, então, identificar o respectivo ponto de contato. Dada sua simplicidade, tal sistema não suporta funções multitoque, uma vez que prevalecerá sempre o primeiro ou o último circuito fechado, dependendo de como for utilizada tal tecnologia; 
- Eletromagnética: o sistema é composto por uma superfície de contato que contém, em sua parte anterior, um conjunto de fios que funcionam como sensores que detectam as alterações eletromagnéticas geradas por uma caneta especial, utilizada para a interação;

- Capacitiva: assim como na tecnologia eletromagnética, existe um barramento de fios presentes por trás da superfície de contato; no entanto, dada sua maior sensibilidade, esse tipo de sistema é capaz de reagir com maior precisão a toque dos dedos, ou de materiais com propriedades eletrostáticas;

- Ultrassônica: essa solução funciona por leitura e sinalização de pulsos ultrassônicos. Cada vez que uma caneta especial entra em contato com uma superfície, esta emite um sinal ultrassônico que será detectado por dois receptores, posicionados nas extremidades da mesma. Um circuito de processamento calcula a localização do ponto de contato considerando o tempo de recepção dos pulsos emitidos pela caneta;

- Infravermelha: embora existam diferentes concepções possíveis, os seus funcionamentos são geralmente similares, a maioria utilizando uma câmera de vídeo com algum tipo de filtro que captura a luz infravermelha emitida por uma caneta especial em uma superfície (LEE, 2008).

Dadas todas essas tecnologias, existem trabalhos que avaliam o uso de soluções de lousas digitais disponíveis no mercado (ZANETTE et al., 2010; GIACOMAZO et al., 2010 e DE CARLI, 2013). Porém, percebe-se que ainda não há muita literatura que aborde especificamente o emprego da captura de luz infravermelha por câmeras de vídeo como tecnologia alternativa para o estabelecimento de lousas interativas (LEE, 2008). Nesse ínterim, particularmente pode-se destacar os trabalhos de Junior (2011) e de Soares (2009).

O primeiro trabalho desenvolveu uma solução baseada em câmera digital e caneta infravermelha e o segundo, criou o sistema LoCoBoard, apresentando uma descrição mais detalhada quanto ao algoritmo empregado e expondo dados sobre testes de desempenho e de precisão do sistema. Já Pereira (2015) descreve um sistema semelhante, porém empregando a câmera infravermelha presente nos joysticks do vídeo game Nintendo Wii como solução de captura.

Apesar dos relativos bons resultados obtidos nos trabalhos citados, o diferencial do presente artigo encontra-se no foco em expor a construção de uma solução que envolva a questão específica do baixo custo, e no fato de apresentar e discutir os resultados de testes de uso do sistema proposto, incluindo usuários com e sem experiências prévias em relação a lousas digitais.

\section{Solução Proposta}

Considerando o baixo custo, no sistema desenvolvido, optou-se pela adoção da tecnologia baseada na captação de luz infravermelha, dispensando o uso de telas sensíveis, conforme já apresentado na Seção 2 deste trabalho.

O modelo proposto tem como principal finalidade a manipulação de uma caneta emissora de luz infravermelha com uma superfície onde é projetada a tela de um computador, fazendo com que o usuário interaja com o mesmo. A seguir são descritos os elementos de hardware e de software que constituem a solução.

\subsection{Hardware}

O sistema de lousa digital proposto apresenta os seguintes componentes (Figura 2): 


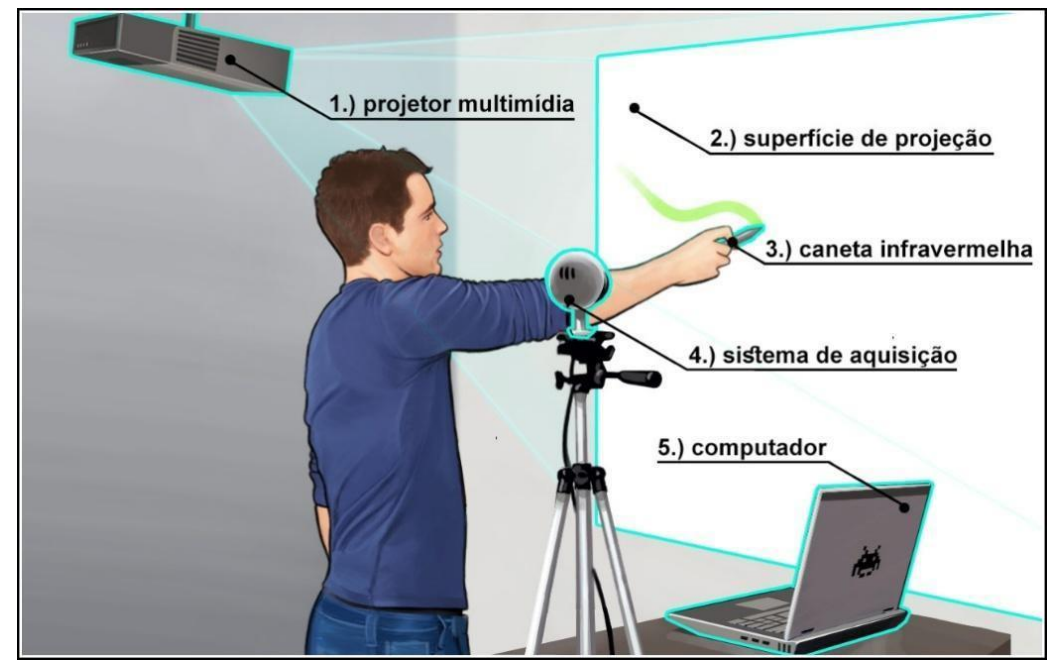

Figura 2 - Disposição dos elementos de hardware do sistema. Fonte: os autores, 2019.

1. Projetor multimídia: responsável por projetar a saída de vídeo de um computador na superfície onde o usuário interage;

2. Superfície de projeção: superfície que reflete a luz do projetor e proporciona o mínimo de atrito e desgaste à ponta da caneta empregada;

3. Caneta infravermelha: dispositivo capaz de emitir luz infravermelha, manipulada pelo usuário a fim de controlar a interação com o computador;

4. Sistema de aquisição: webcam com lente modificada, através de filtro, para acentuar a sensibilidade ao infravermelho e atenuar a luz visível capturada;

5. Computador: equipamento cujo usuário interage através do sistema.

A caneta luminosa é constituída por uma carcaça de plástico, impressa numa impressora 3D, e por um circuito simples, com um botão ligado a um LED infravermelho, alimentado por uma pilha comum (Figura 3).

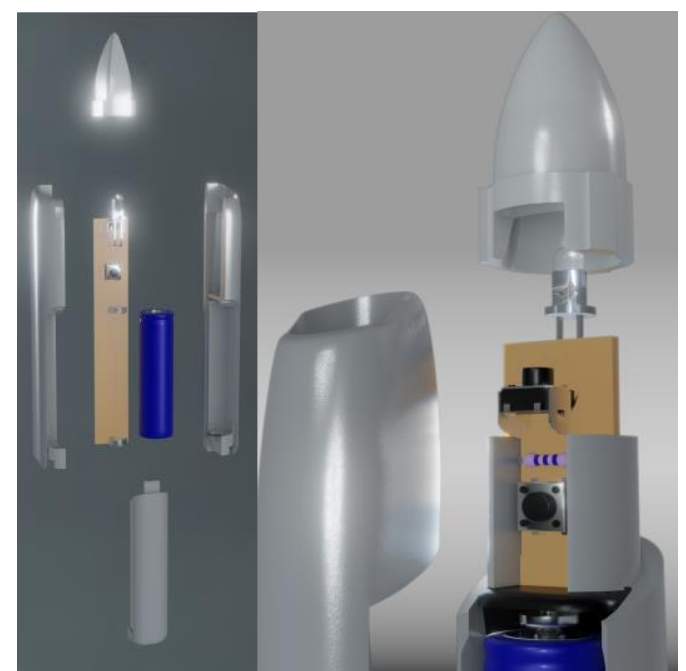

Figura 3 - Componentes da caneta desenvolvida, à esquerda; e detalhe do circuito, à direita. Fonte: os autores, 2019.

Ao se pressionar a caneta sobre a superfície de projeção, o botão é ativado, acendendo o LED, que emite luz infravermelha. Essa luz, invisível ao olho humano, é então captada por uma webcam, cuja lente foi modificada com a inclusão de um filtro específico para luz infravermelha. Esse filtro altera a recepção da imagem captada, barrando a luz visível e deixando passar somente os pontos de luz infravermelha emitidos pelo LED da caneta (Figura V. $17 \mathrm{~N}^{\mathrm{o}}$ 3, dezembro, 2019 RENOTE DOI: 
4). A imagem captada pela webcam é, então, processada através de um software próprio (discutido mais adiante na Seção 3.2) e, por fim, ocorre a interação com o computador utilizado, que projeta sua imagem sobre a superfície.

É importante destacar que o custo envolvido na criação desse sistema foi bastante baixo: a webcam empregada, incluindo o filtro de infravermelho, apresentou custo total aproximado de US\$ 35,00 e a caneta, US\$30,00, incluindo o filamento de impressão 3D utilizado, o LED infravermelho e a respectiva instalação eletrônica do circuito. Percebe-se que a solução adotada apresenta uma redução substancial de custos, principalmente se comparados a produtos vendidos no mercado.

Deve-se salientar que pode haver uma redução ainda maior do valor envolvido na produção da caneta se forem empregados processos industriais, como o uso de injeção plástica para a carcaça e de placas de circuito pré-definidas para a instalação eletrônica.

\subsection{Software}

Para o correto funcionamento do sistema desenvolvido, foi criado um software específico, que executa a seguinte sequência de operações:
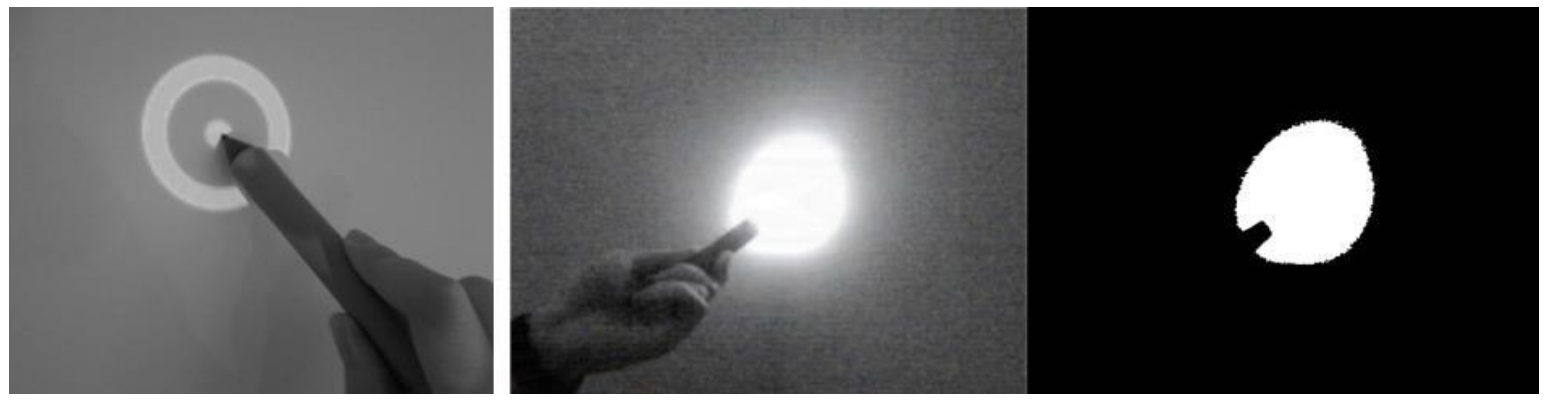

Figura 4 -Exemplo de um ponto para calibração (à esquerda). Imagem original (ao centro) e respectiva imagem gerada pelo processo de binarização por limiarização (à direita).

Fonte: os autores, 2019.

1. Calibração para a correção da perspectiva de projeção: necessária para compensar a deformação de perspectiva causada pelo posicionamento da webcam em relação à projeção. O software inicialmente projeta uma imagem escura com alvos coloridos (Figura 4) sobre os quais o usuário deve pressionar a caneta. Um alvo é exibido por vez, sendo liberado um novo alvo quando o acionamento da caneta é detectado. São necessários quatro pontos para a calibração, sendo gerada uma matriz homográfica para correção da perspectiva de projeção (DANTAS, 2015);

2. Captura do sinal de vídeo: colhe o sinal de vídeo captado pela webcam, transformando-o em imagens individuais e convertendo-as em escala de cinza para a realização do restante do processamento (MARQUES FILHO; VIEIRA NETO, 1999);

3. Binarização por limiarização: divisão da imagem digital capturada em duas regiões distintas, baseada na comparação simples entre os níveis de cinza dos pixels de cada imagem com relação a um determinado valor, o limiar, fornecido pelo usuário. Assim, essa etapa separa os pixels correspondentes à luz infravermelha dos demais. Ao final, é gerada uma imagem binária correspondente, cujos pixels assumem a cor branca para a luz emitida pela caneta e preta para o restante (Figura 4);

4. Extração de coordenadas cartesianas: após o processo anterior, é gerada uma imagem que apresenta uma elevada concentração de pixels de cor branca ao redor do local onde a luz infravermelha é representada na imagem originalmente capturada. Ao se percorrer essa imagem binária, pode-se obter o centro da região referente à luz infravermelha, bastandose calcular separadamente a média aritmética das coordenadas horizontais e verticais do respectivo conjunto de pixels; 
5. Homografia: transformação projetiva, considerando a matriz homográfica gerada anteriormente, utilizada para a correção de perspectiva (DANTAS, 2015). Nessa etapa, o centro da região referente à luz infravermelha, obtido anteriormente, é convertido de coordenadas da projeção capturada pela webcam para as coordenadas da tela do computador que origina a projeção;

6. Emulação do mouse: o software move o cursor do mouse para a posição referente ao centro nas coordenadas de tela do computador e realiza um clique na mesma, então concluindo a interação.

\section{Testes e Resultados Obtidos}

O protótipo desenvolvido foi submetido a dois testes específicos com voluntários de diferentes perfis. No primeiro teste, realizado com dezessete estudantes, que nunca haviam utilizado uma lousa digital, o objetivo foi avaliar possíveis falhas de captura oriundas da provável oclusão (obstrução visual pela sobreposição física entre corpos) da luz infravermelha emitida pela caneta por partes do corpo do próprio usuário. O segundo teste, realizado com três docentes com experiência anterior com outros modelos de lousas digitais, teve como finalidade avaliar a eficiência da solução desenvolvida em relação à manipulação de conteúdos digitais. A seguir é apresentada a preparação dos ambientes para a realização dos testes bem como a discussão de cada um dos mesmos.

\subsection{Preparação dos Ambientes de Testes}

Experimentos preliminares demonstraram que o posicionamento frontal da webcam, diretamente ortogonal à tela de projeção, apresentou maus resultados de captura. Isso ocorria devido à localização do usuário e a forma com que o mesmo normalmente se movia ao manipular a caneta, podendo ocorrer oclusão gerada por suas costas ou mãos.

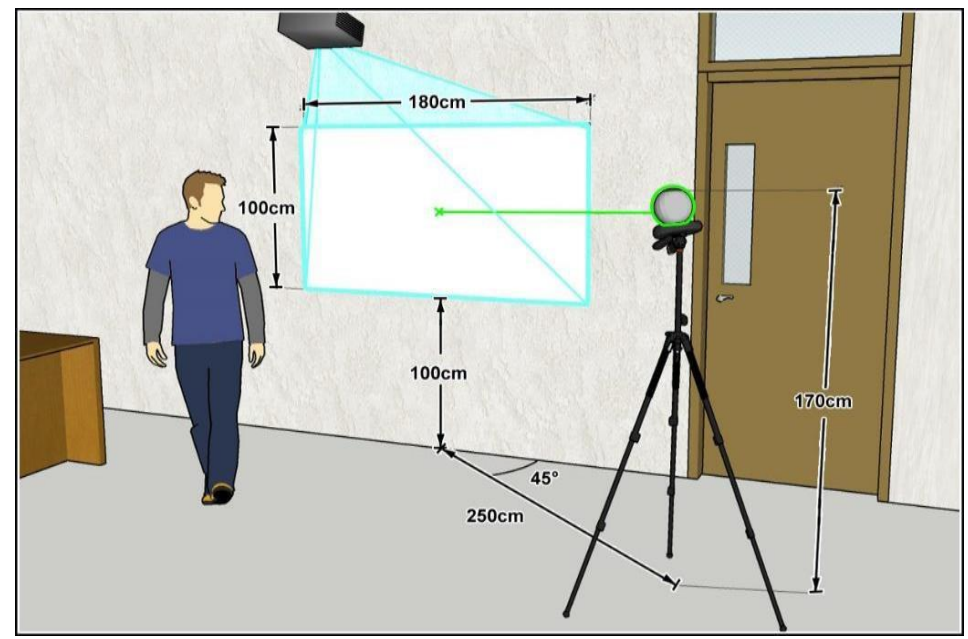

Figura 5 - Posições e dimensões dos elementos utilizados no teste.

Fonte: os autores, 2019.

Optou-se, então, por utilizar a webcam instalada num tripé posicionado diagonalmente em relação à projeção, o que acabou minimizando os efeitos de oclusão. A Figura 5 apresenta as posições e as dimensões dos elementos utilizados nos testes.

\subsection{Teste com Estudantes}

Para o primeiro teste, foram selecionados dezessete voluntários, sem experiência prévia com o uso de lousas digitais, estudantes de duas diferentes instituições de ensino: sete, com idades entre 13 e 18 anos, da Escola Estadual de Educação Profissional Jaime Alencar de V. $17 \mathrm{~N}^{\circ}$ 3, dezembro, 2019 RENOTE DOI: 
Oliveira, em Fortaleza, Ceará; e dez, com idades entre 18 e 23 anos, do Curso de Bacharelado em Sistemas e Mídias Digitais da Universidade Federal do Ceará. Os testes ocorreram em salas de aula comuns, que empregavam quadros de fórmica branca, nos locais de origem dos participantes.

A amostra obtida é do tipo não-probabilística e de conveniência, pois os participantes se encontravam diretamente acessíveis aos pesquisadores que realizaram os testes (LAKATOS E. MARCONI, 2017).

No teste efetuado, a primeira tarefa do voluntário foi calibrar o sistema. Após isso, era necessário preencher um caça-palavras que apresentava nomes de quatro cores (amarelo, azul, verde e vermelho). O objetivo desta ação era, arrastando a caneta sobre a tela de projeção, marcar cada nome com sua respectiva cor. Para tanto, foi utilizada a aplicação Open-Sankoré (https://relia.org.br/open-sankore), que disponibiliza uma função de marcador cuja sobreposição intensifica a tonalidade da cor utilizada. As imagens resultantes, posteriormente transformadas em tons de cinza, indicam diretamente as possíveis falhas no traçado (Figura 6).

Falhas de traçado

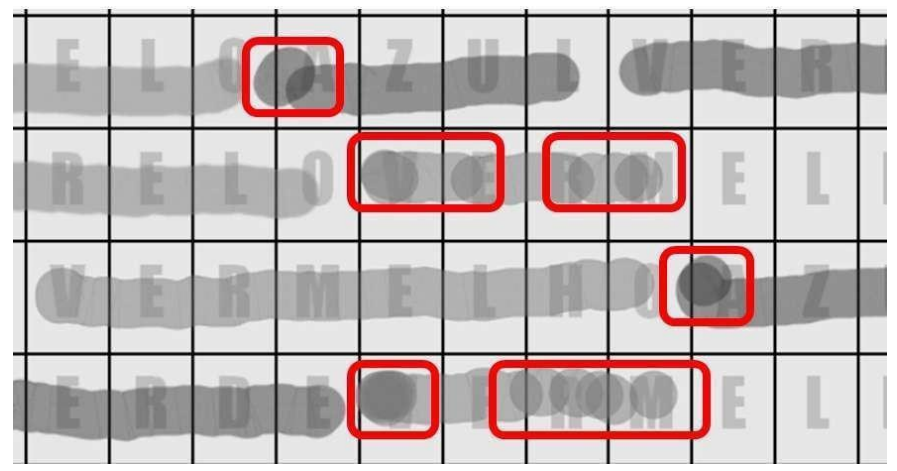

Figura 6 - Exemplos de falhas no traçado obtidas no primeiro teste.

Fonte: os autores, 2019.

A Tabela 1 apresenta os resultados gerais da avaliação das imagens obtidas com relação ao preenchimento do caca-palavras.

Tabela 1 - Dados sobre o desempenho dos participantes do teste.

\begin{tabular}{ccccc}
\hline Variável & $\begin{array}{c}\text { Falhas no } \\
\text { inicio }\end{array}$ & $\begin{array}{c}\text { Falhas no } \\
\text { meio }\end{array}$ & $\begin{array}{c}\text { Falhas no } \\
\text { final }\end{array}$ & $\begin{array}{c}\text { Total de } \\
\text { falhas }\end{array}$ \\
\hline $\begin{array}{c}\text { Média de falhas por } \\
\text { individuo }\end{array}$ & 2,35 & 1,29 & 1,35 & 5,00 \\
$\begin{array}{c}\text { Desvio Padrão } \\
\text { Tempo médio em minutos }\end{array}$ & 2,50 & 2,02 & 1,73 & 4,81 \\
Média de falhas por minuto & 5,00 & 5,00 & 5,00 & 5,00 \\
\hline
\end{tabular}

De uma forma geral, uma falha no traçado significou que o sistema não foi capaz de reconhecer a luz infravermelha emitida pela caneta. No entanto, considerando uma análise quantitativa dos resultados obtidos, percebe-se que a quantidade total de erros cometidos foi bastante pequena, ocorrendo, em média, somente um erro por minuto para cada participante.

Levando em conta o uso do sistema, tais falhas podem ter sido causadas por um dos seguintes fatores específicos:

- Oclusão: devido à forma de cada usuário escrever e inclinar a mão ou o corpo com relação à tela de projeção; 
- Falha de arraste: ao clicar e arrastar a caneta, é necessário manter certa pressão sobre a superfície para manter o LED aceso. Ocasionalmente, no momento de arrastar, alguns usuários podem ter reduzido a pressão, apagando o LED;

- Considerando esses dois fatores, as falhas apresentadas na Tabela 1 puderam ser classificadas em três categorias:

- Falhas no início das palavras (47\%): apontam para falha de arraste, uma vez que ocorrem logo após o início da manipulação da caneta;

- Falhas no meio das palavras (26\%): provavelmente causadas por oclusão devido à movimentação do corpo do usuário;

- Falha no fim das palavras (27\%): provavelmente causadas por oclusão devido à movimentação da mão do usuário.

Pode-se notar que a maioria das falhas ficou situada entre o meio e o final das palavras, totalizando $53 \%$, o que indica que a oclusão acontece mais frequentemente do que possíveis falhas no uso da caneta (falhas de arraste). No entanto, nota-se que o elevado percentual de falhas no início das palavras $(47 \%)$ sugere que ainda cabem modificações no protótipo da caneta, a fim de melhorar o acionamento de seu LED infravermelho.

Já considerando a distribuição espacial das falhas, sobrepondo-se todos os traçados realizados pelos participantes do teste, obteve-se o mapa de calor (WILKINSON, 2009) apresentado na Figura 7, onde as regiões mais escuras representam maior frequência de falhas.

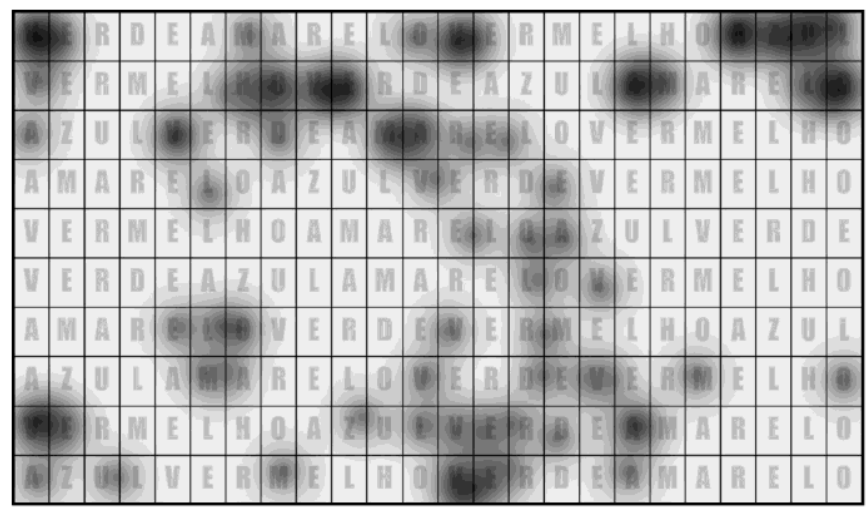

Figura 7 - Mapa de calor mostrando a distribuição espacial de falhas de traçado.

Fonte: os autores, 2019.

Percebe-se que a maioria das falhas ocorre nas extremidades superiores da projeção. No canto esquerdo superior, considerando a distribuição dos elementos apresentada na Seção 4.1, as falhas possivelmente ocorrem devido à maior distância da câmera e consequente dificuldade para captura correta. E no canto direito superior, as falhas podem advir da inclinação da mão de algumas pessoas, particularmente as destras.

\subsection{Teste com Docentes}

Dados os bons resultados do primeiro teste, procedeu-se um segundo teste com a participação de três docentes também do Curso de Bacharelado em Sistemas e Mídias Digitais da Universidade Federal do Ceará, que já possuíam experiência no uso de lousas digitais.

Mais uma vez, a amostra obtida é do tipo não-probabilística e de conveniência, pois os participantes se encontravam diretamente acessíveis aos pesquisadores que realizaram os testes (LAKATOS E. MARCONI, 2017).

A fim de complementar os resultados obtidos no teste anterior, optou-se por instalar o sistema numa sala que possuía uma lousa de vidro, que normalmente não é suportada pela maioria das soluções comerciais, foi replicado o mesmo posicionamento de equipamentos já descrito na Seção 4.1. 
Empregando o sistema, foi solicitado a cada um dos docentes a realização da seguinte sequência de operações:

1. Calibrar o sistema;

2. Empregando o software LibreOffice (https://pt-br.libreoffice.org), elaborar uma apresentação simples, contendo três slides, sobre o bairro onde mora e, posteriormente, apresentar a mesma;

3. Criar elementos gráficos simples (um retângulo, uma elipse e um triângulo) com diferentes tipos e cores de preenchimentos na ferramenta online SumoPaint (https://www.sumopaint.com);

4. Montar um dos quebra-cabeça disponíveis no website http://www.toupty.com;

5. Acessar, informando login/senha, um sistema online para a criação de uma aula fictícia, com tema livre, incluindo a criação de um título e uma breve descrição, e a inclusão de um arquivo PDF.

Para a inserção de textos, foi utilizado um teclado virtual, fornecido pelo próprio Microsoft Windows, sistema operacional utilizado nos testes, apresentado diretamente na projeção. Após a realização das atividades, os participantes foram incentivados a discutir suas impressões acerca do uso do sistema, incluindo a comparação com os modelos comerciais utilizados anteriormente, destacando principais vantagens e desvantagens observadas. Todo o processo foi devidamente documentado em vídeo e demandou cerca de 40 minutos, por participante, incluindo a discussão de suas impressões de uso.

De uma forma geral, e do ponto de vista qualitativo, o sistema proposto foi bem avaliado, sendo destacada a facilidade de calibragem inicial, considerada mais simples que a maioria dos modelos comerciais. A caneta utilizada foi considerada adequada, porém um dos participantes sentiu falta de um LED colorido para informar o correto funcionamento da mesma. Os participantes ficaram bastante satisfeitos com o baixo custo envolvido e destacaram, ainda, uma questão ecológica. Tal questão refere-se à possibilidade da substituição praticamente total de giz, marcadores e apagador, evitando o comum descarte de tais materiais. A fim de fomentar ainda tal apelo ecológico, dois dos docentes indicaram a substituição das pilhas comuns utilizadas por modelos recarregáveis.

Com relação especificamente à caneta, um docente comentou sobre sua simplicidade de construção, informando que a maioria dos modelos utilizados comercialmente simplesmente não pode ser reparada em caso de problemas, precisando ser substituída. Já um outro docente achou que a caneta utilizada era bastante superior na questão de ergonomia e de baixo peso, comparando-a com outros modelos utilizados previamente.

Todos os três participantes consideraram simples o emprego do sistema como um todo, mas indicaram que seria interessante a produção de algum tipo de tutorial específico para uso por iniciantes. Além disso, eles também aconselharam o desenvolvimento de um software específico para complementar a operação, uma vez que sentiram falta de recursos como captura e edição de telas, geralmente presente em sistemas comerciais. Os três participantes criticaram a necessidade constante de reposicionamento do teclado virtual, sendo mais interessante a adoção de um modelo que pudesse ser exibido e ocultado de acordo com o uso. Tal recurso também poderia estar disponível no software complementar.

Apesar do aspecto qualitativo desse teste, percebeu-se que a proporção de falhas observadas foi similar àquela observada no teste anterior, realizado com estudantes.

\section{Conclusões}

O presente trabalho expôs uma alternativa de solução para produzir um sistema de baixo custo de lousa digital, empregando tecnologia de captura de luz infravermelha, que possa ser utilizado como recurso didático para instituições de ensino.

Algumas vantagens destacadas nos testes realizados, como a simplicidade de operação, desde a fase de calibração até o uso propriamente dito, o baixo custo de disponibilização junto 
às poucas falhas de captura, destacam o instrumento desenvolvido como uma boa solução em relação a outros produtos semelhantes, inclusive comerciais.

No entanto, observando os resultados apresentados, podem ser elencados ainda alguns possíveis refinamentos a serem realizados em trabalhos futuros:

- Criação de software complementar de uso, fornecendo recursos de captura e edição de telas e disponibilização de teclado virtual;

- Substituição do uso da caneta por emissor laser infravermelho para operação a distância, aproveitando-se do atual sistema de captura;

- Adaptação da ponta da caneta para operação em outras superfícies, como paredes comuns ou mesmo aparelhos de TV, em substituição ao emprego de quadros de fórmica, lousas de vidro e afins, minimizando ainda mais os custos envolvidos;

- Avaliação do emprego da solução em salas de aula.

Com tais aprimoramentos, acredita-se que informações sobre o modelo proposto possam ser futuramente disponibilizadas, sob licença de software e de hardware livres, para replicação por indivíduos ou instituições interessadas. Assim, espera-se que a solução aqui proposta possa evoluir de tal forma a se consolidar como uma opção alternativa de ferramenta voltada a uma maior democratização do processo de ensino-aprendizagem otimizado.

\section{Referências}

DANTAS, P. F. S. Lousa digital baseada em visão computacional. 2015. 57p. Monografia (Bacharelado em Sistemas de Informação) - Universidade Federal do Ceará, Quixadá, 2015. Disponível: http://www.lbd.dcc.ufmg.br/colecoes/wvc/2012/0021.pdf

DE CARLI, D. Reflexões sobre a lousa digital como recurso pedagógico a partir da abordagem sociointeracionista. Colabor@-A Revista Digital da CVA-RICESU, 8(31).2013.

GIACOMAZZO, G. F. et al. Aplicações para a Ferramenta de Avaliação Online Quiz na UNESC. RENOTE, RENOTE, 8(3). 2010.

JUNIOR, J. C. D. C. Lousa interativa de alta resolução. Revista Sapere. Tatuí, v.3, n.1, p.1-5, 2011.

LAKATOS, E. M.; MARCONI, M. A. Fundamentos de Metodologia Científica. 2017.

LEE, J. C. Hacking the Nintendo Wii Remote. IEEE Pervasive Computing, vol. 7, no. 3, pp. 39-45, July-Sept. 2008. doi: 10.1109/MPRV.2008.53

MARQUES FILHO, O.; VIEIRA NETO, H. Processamento Digital de Imagens. Rio de Janeiro: Brasport, 1999.

PEREIRA, A. R. Uso de sistema interativo baseado em projetor multimídia e controle "Wiimote" do nintedo em aulas de química. 2015. 32 p. Monografia (Licenciatura em Química) - Universidade Federal de Viçosa, Viçosa, MG, 2015.

SOARES, C. P. A. LoCoBoard: Low-Cost Interactive Whiteboard Using Computer Vision Algorithms. Fernando Pessoa: Universidade Fernando Pessoa, 2009. Disponível em: <http://bdigital.ufp.pt/bitstream/10284/1228/1/ DM_ChristopheSoares.pdf >. Acesso em: 12 set. 2019.

WILKINSON, L.; FRIENDLY, M. The history of the cluster heat map. The American Statistician 63.2 (2009): 179-184.

ZANETTE, E. N.; NICOLEIT, E. R.; GIACOMAZZO, G. F.; FIUZA, P. J.; DOSSANTOS, C. R. Construindo novas interações: AVA e lousa digital interativa no ensino superior. RENOTE, 8(2). 2010. 